\title{
Regional cerebral blood flow changes after bilateral external carotid artery ligation in acute experimental infarction ${ }^{1}$
}

\author{
JACOB ABRAHAM ${ }^{2}$, ERWIN O. OTT ${ }^{3}$, MINORU AOYAGI, \\ YUKIO TAGASHIRA, AMRIT N. ACHARI, AND JOHN STIRLING MEYER \\ From the Department of Neurology, Baylor College of Medicine, \\ and the Baylor-Methodist Center for Cerebrovascular Research, Houston, Texas, U.S.A.
}

SYNOPSIS Regional cerebral blood flow (rCBF) was measured in baboons by intracarotid injection of ${ }^{133} \mathrm{Xe}$ and a gamma camera after acute cerebral infarction was induced by occlusion of the middle cerebral artery (MCA). A steady state $\mathrm{rCBF}$ was measured four hours after MCA occlusion and was followed by bilateral ligation of the external carotid arteries (ECA). Subsequent rCBF measurements were obtained at 30, 60, and 120 minutes. After bilateral ECA ligation, flow in $\dot{\infty}_{\infty}$ ischaemic and non-ischaemic areas was greatly enhanced and flow in the hyperaemic areas signifto:cantly reduced, presumably since they had provided collateral circulation to the ischaemic zone wit $\overline{\text { i }} \infty$ a favourable redistribution.

Bilateral external carotid artery ligation in primates and in man increases blood flow in the internal carotid artery (ICA) (Abraham et al., 1971). This observation is understandable when one considers the magnitude of blood flow changes likely to occur in the ICA when a significant outflow tract and extracranial collateral vascular bed of the external carotid artery (ECA) is occluded bilaterally. Nevertheless, it is unknown whether in this situation any change occurs in cerebral tissue perfusion (regional cerebral blood flow) in the territory supplied by the ipsilateral ICA, despite some beneficial changes in the neurological status reported in 20 patients with occlusion of the middle cerebral artery (MCA) or its branches (Abraham and Daniel, 1972).

\footnotetext{
1 This work was supported by Grant NS 09287 from the National Institute of Neurological Diseases and Stroke, and in part by Grant RR 00350 from the General Clinical Research Centers Branch, Division of Research Resources, National Institutes of Health, Bethesda, Maryland 20014, U.S.A.

2 Present address: Department of Neurological Sciences, Christian Medical College Hospital, Vellore, S. India.

3 Present address: Department of Neurology, University Clinic of Neurology and Psychiatry, Graz, Austria.

(Accepted 9 August 1974).
}

Certain limitation in attempts to increase cerebral blood flow (CBF) in man and experer mental animals by increasing perfusion pressue are possibly due to autoregulation (Simeone ov al., 1972) and a greater vasoreactivity of the ECA. to many pharmacological agents (Farhat and Schneider, 1967) due to their richer sympathetic innervation (Meyer et al., 1967; Harper et al., 1972).

This communication reports in detail measurements of regional cerebral blood flow (rCBF) in $\frac{\text { 의 }}{3}$ baboons in which acute cerebral infarction was induced by occlusion of the MCA before and after ligation of the external carotid arteries bilaterally.

\section{METHODS}

Nine baboons (Papio anubis) of either sex weighing 8-10 kg were anaesthetized with pentobarbitone (30윽 $\mathrm{mg} / \mathrm{kg}$ intravenously or intraperitoneally); $1-2 \mathrm{ml}$ of $\supset$ supplemental intravenous pentobarbitone $(30 \mathrm{mg}$ inㅡㅡㅡ. $10 \mathrm{ml}$ normal saline) was given three to four times N during the experiment to maintain continuousanaesthesia. Tracheostomy was performed and the $\tilde{O}$ animal breathed spontaneously. If the recorded $\mathrm{PaCO}_{2}$ level was inconstant, the animal was im- 
mobilized with gallamine ( $10 \mathrm{mg} / \mathrm{kg}$ intravenously) and respiration controlled to maintain $\mathrm{PaCO}_{2}$ constant by means of a Harvard variable speed respirator. A polyethylene catheter introduced into the aorta via one femoral artery was utilized to record arterial blood pressure with a Statham pressure transducer. A Teflon-tipped metal cannula was used to measure arterial $\mathrm{PO}_{2}$ and $\mathrm{PCO}_{2}$ by use of a mass spectrometer (Medspect MS-8) (Brantigan et al., 1972 ) inserted into the other femoral artery. A polyethylene catheter was introduced into the femoral vein for administration of intravenous fluids and supplemental pentobarbitone.

Superior sagittal sinus wedge pressure was measured by means of a small indwelling polyethylene catheter connected to a pressure transducer. The body temperature of the animal was maintained by heating pads at circa $36.8^{\circ} \mathrm{C}$. Tracheal end tidal $\mathrm{CO}_{2}$ was monitored with a Beckman infrared gas analyzer. All parameters were recorded continuously by means of a Grass polygraph.

The right (R) MCA was approached by enlarging the optic canal and occluded with a silver clip using a Zeiss operating microscope (Hudgins and Garcia, 1970). The carotid arteries were exposed bilaterally taking meticulous care to preserve the sympathetic chain and the vagus nerves so that heart rate and pupillary size were not altered. The right linguofacial artery was cannulated with a polyethylene catheter and its tip placed circa $0.5 \mathrm{~cm}$ below the bifurcation of the common carotid artery. All other branches of

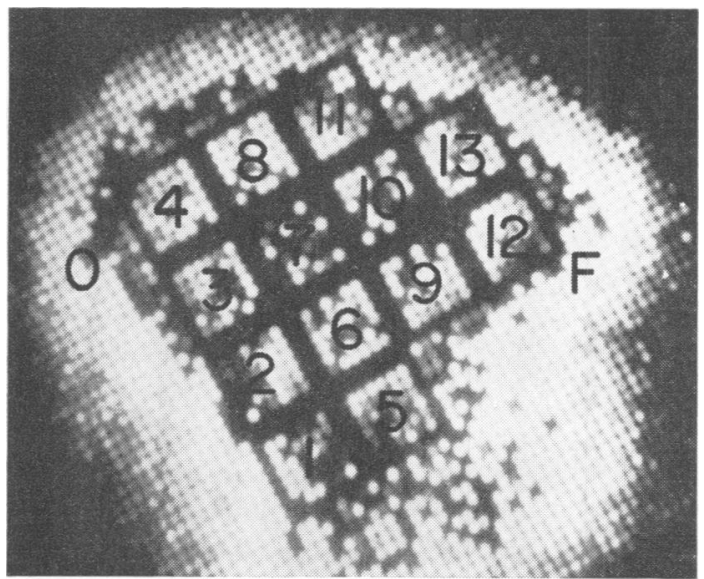

FIG. 1 Typical scintiphoto of ${ }^{133}$ Xe clearance as $t h^{e}$ radionuclide appeared on the grid soon after the carotid injection. $\mathrm{O}=$ occipital pole. $F=$ frontal. Numbers $=$ selected regions. the RECA were ligated. The left (L) ECA and its branches were dissected and ligatures placed loosely around them. Skin and temporalis muscle including the periosteum were resected to expose the entire extent of the right calvarium.

Regional cerebral blood flow ( $\mathrm{rCBF}$ ) was measured by intracarotid injection of ${ }^{133} \mathrm{Xe}$ and the gamma camera (Mathew et al., 1972). An outline of the baboon's skull was marked on the collimator and its main axis was matched with that of the baboon's head in a standard manner. A standard grid for assessment of 13 selected regions was used from one animal to another. A $1 \mathrm{ml}$ bolus of ${ }^{133} \mathrm{Xe}(2-2.5 \mathrm{mCi})$ was then injected via the catheter in the linguofacial artery and the clearance curve recorded over the ensuing 10 minute interval on a magnetic tape.

In order to define accurately the zone of $\mathrm{rCBF}$ supplied by the MCA, the distal stump of the MCA was cannulated at the time of occlusion in two animals and, 30 minutes after the evaluation of the steady state (see Fig. $8 \mathrm{a})$, a small bolus $(0.25 \mathrm{ml})$ was injected into the stump and the clearance measurement repeated (Fig. 8b).

At the end of the study the data were replayed permitting computer analysis of the 13 selected regions in the ischaemic hemisphere (Fig. 1). Flow values were calculated from clearance curves for both stochastic $\left(\mathrm{rCBF}_{10}\right)$ and compartmental analysis automatically by a computer (Heiss et al., 1972; Mathew et al., 1972).

The experimental design was as follows: four hours after MCA occlusion, the lateral aspect of the baboon's head was placed on the collimator of the gamma camera and fixed in position. Once positioned, no movement was permitted until the experiment was completed. Measurements of $\mathrm{rCBF}$ were made in the steady state followed by ligation of the LECA so that both ECA were now occluded and rCBF measurements were repeated 30,60 , and 120

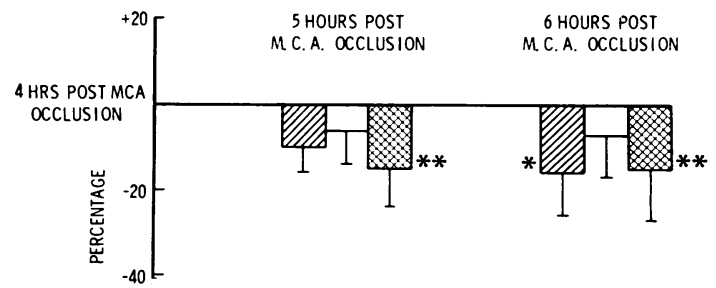

FIG. 2 Percentage change in $r C B F_{10}$ middle cerebral artery occlusion without bilateral ECA occlusion.

$* P<0.05$. ** $P<0.025$. Hatching = non-ischaemic area. White = ischaemic area. Cross-hatching = hyperaemic area. $S S=$ steady state (four hours after $M C A$ occlusion). 
TABLE 1

MEAN REGIONAL FLOW VALUES IN 13 REGIONS OF INTEREST AFTER MIDDLE CEREBRAL ARTERY OCCLUSION

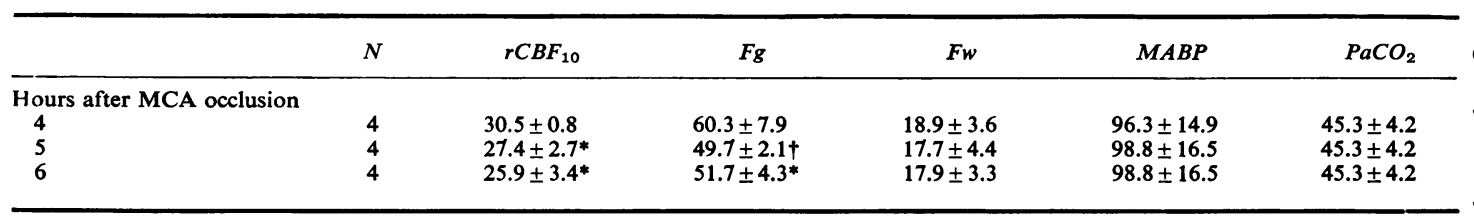

$N=$ number of cases.

Blood flow values $=$ mean \pm standard deviation $(\mathrm{ml} / 100 \mathrm{~g}$ brain $/ \mathrm{min})$.

$\mathrm{MABP}=$ mean arterial blood pressure $(\mathrm{mmHg})$.

* Statistically significant compared with four hours after MCA occlusion $(P<0.05)$.

$\uparrow$ Statistically significant compared with four hours after MCA occlusion $(P<0.01)$.

TABLE 2

MEAN REGIONAL FLOW VALUES IN 13 REGIONS OF INTEREST AFTER MIDDLE CEREBRAL ARTERY OCCLUSION FOLLOWED BY BILATERAL EXTERNAL CAROTID ARTERY LIGATION

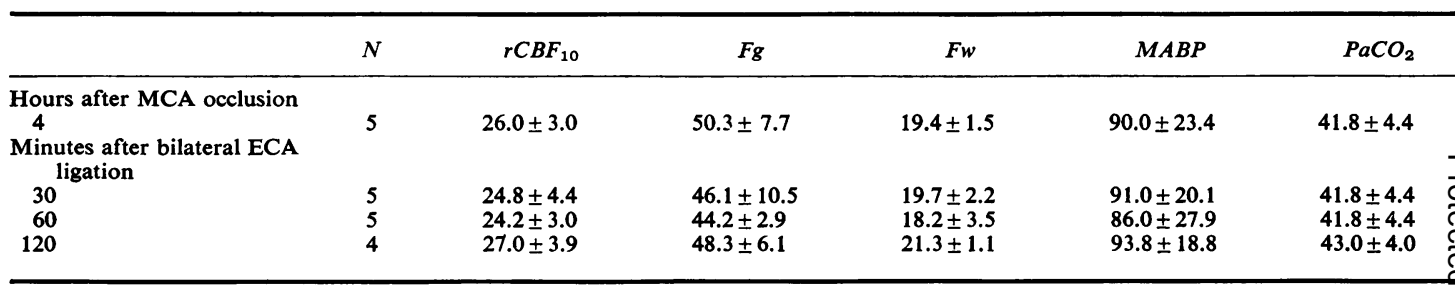

$N=$ number of cases. Units as in Table 1 .

minutes after ligation. Samples of arterial and cerebral venous blood were taken intermittently for estimation of $\mathrm{PCO}_{2}, \mathrm{PO}_{2}$, haemoglobin, and haematocrit levels. After the measurements the animal was killed by a lethal dose of intravenous pentobarbitone and the brain removed at necropsy and sectioned to determine the extent of the infarction and to verify the correct placement of the clip on the MCA.

The same procedure was performed in a control series of baboons, except that ligature of the LECA was omitted. This control group served for comparison of rCBF in areas of ischaemia and hyperaemia and their evolution after occlusion of RMCA and RECA compared with animals subjected to bilateral ECA ligation.

\section{RESULTS}

Computer analysis was performed from the clearance of ${ }^{133} \mathrm{Xe}$ from the hemisphere in the 13 selected regions in all nine animals as illustrated (Fig. 1). Mean flow values in the 13 regions measured four, five, and six hours after occlusion showed progressive reduction of hemispheric blood flow (HBF) in the control group (Table despite relatively constant blood pressure and of $\mathrm{PaCO}_{2}$.

Bilateral external carotid artery ligation in the experimental series was performed four hours

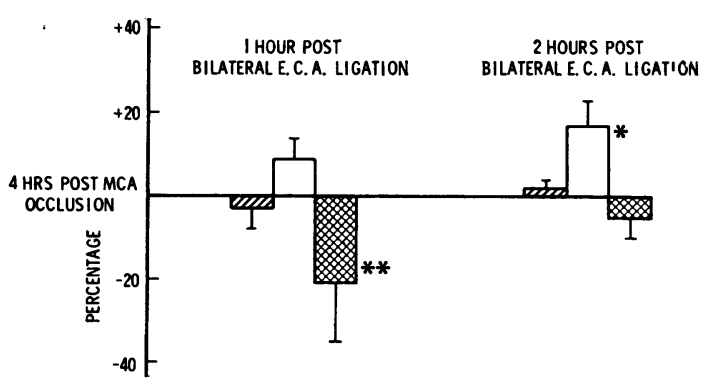

FIG. 3 Percentage change in $r \mathrm{CBF}_{10}$ after middle cerebral artery occlusion followed by bilateral external carotid artery ligation.

${ }^{*} P<0.05 .{ }^{* *} P<0.025$. Hatching = non-ischaemic ô area. White $=$ ischaemic area. Cross-hatching $=$ hyper- $N$ aemic area. $S S=$ steady state (four hours after MCA occlusion). 
TABLE 3

MEAN REGIONAL FLOW VALUES IN ISCHAEMIC AREA AFTER MIDDLE CEREBRAL ARTERY OCCLUSION

\begin{tabular}{lcccccc}
\hline & $N$ & $r C B F_{10}$ & $F g$ & $F w$ & $M A B P$ & $P a C O_{2}$ \\
\hline Hours after MCA occlusion & & & & & & \\
4 & 4 & $25.8 \pm 2.2$ & $36.9 \pm 4.1$ & $14.4 \pm 4.6$ & $96.3 \pm 14.9$ & $45.3 \pm 4.2$ \\
5 & 4 & $24.4 \pm 3.3$ & $41.6 \pm 10.1$ & $14.9 \pm 6.8$ & $98.8 \pm 16.5$ & $45.3 \pm 4.2$ \\
6 & 4 & $23.9 \pm 5.1$ & $42.3 \pm 4.6$ & $17.7 \pm 6.0$ & $98.8 \pm 16.5$ & $45.3 \pm 4.2$ \\
\hline
\end{tabular}

$N=$ Number of cases. Units as in Table 1.

TABLE 4

MEAN REGIONAL FLOW VALUES IN ISCHAEMIC AREA AFTER MIDDLE CEREBRAL ARTERY OCCLUSION FOLLOWED BY EXTERNAL CAROTID ARTERY LIGATION

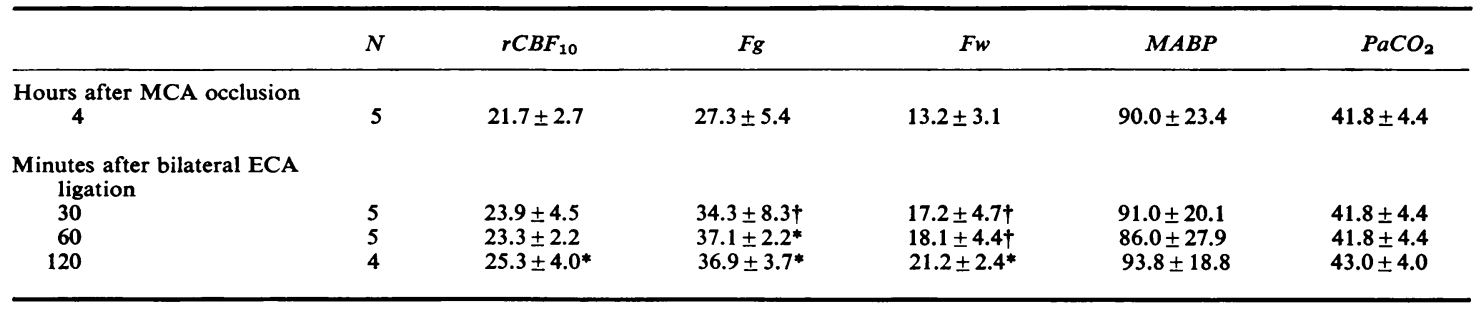

$N=$ Number of cases. Units as in Table 1.

* Statistically significant compared with four hours MCA occlusion $(P<0.05)$

$\dagger$ Statistically significant compared with four hours MCA occlusion $(P<0.05)$.

TABLE 5

MEAN REGIONAL FLOW VALUES IN HYPERAEMIC AREA AFTER MIDDLE CEREBRAL ARTERY OCCLUSION

\begin{tabular}{|c|c|c|c|c|c|c|}
\hline & $N$ & $r C B F_{10}$ & $F g$ & $F w$ & $M A B P$ & $\mathrm{PaCO}_{2}$ \\
\hline \multicolumn{7}{|c|}{ Hours after MCA occlusion } \\
\hline 4 & 4 & $35.6 \pm 1.4$ & $105.2 \pm 3.1$ & $26.9 \pm 2.5$ & $96.3 \pm 14.9$ & $45.3 \pm 4.2$ \\
\hline 5 & 4 & $30.7 \pm 2.5^{*}$ & $71.3 \pm 49.0^{*}$ & $21.7 \pm 4.5^{*}$ & $98.8 \pm 16.5$ & $45.3 \pm 4.2$ \\
\hline 6 & 4 & $30.1 \pm 4.9^{*}$ & $52.7 \pm 5.7^{*}$ & $19.2 \pm 3.3^{*}$ & $98.8 \pm 16.5$ & $45.3 \pm 4.2$ \\
\hline
\end{tabular}

$N=$ Number of cases. Units as in Table 1.

* Statistically significant compared $w$ th four hours MCA occlusion $(P<0.025)$.

after infarction and $\mathrm{rCBF}$ was measured 30 minutes, one and two hours after bilateral ECA ligation (Table 2). The significant decrease of $\mathrm{rCBF}_{10}$ and grey matter blood flow seen in the control group was no longer apparent in the experimental group.

Detailed analysis of $\mathrm{rCBF}$ changes was undertaken in areas considered to be ischaemic, hyperaemic, or essentially unchanged after MCA occlusion.

In a series of six normal monkeys without
MCA occlusion, interregional differences in rCBF were measured in the same manner and the interregional coefficient of variation (ICV) was $8.3 \pm 0.92 \%$. An ICV of $20 \%$ ( $>2$ SD) or more in the infarcted group was therefore considered to be abnormal. Hence regions with rCBF reduced by more than $20 \%$ of steady state values were classified as 'ischaemic' and those with rCBF increased $20 \%$ above the mean were classified as 'hyperaemic'; the remaining were considered to be 'non-ischaemic'. 


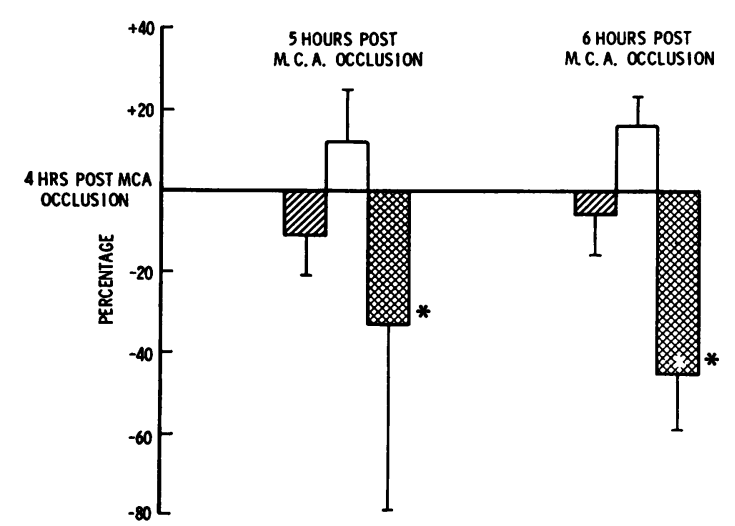

FIG. 4 Percentage change in grey matter flow after middle cerebral artery occlusion without bilateral ECA occlusion.

* $P>0.025$. Hatching $=$ non-ischaemicarea. White $=$ ischaemic area. Cross-hatching =hyperaemic area. $S S=$ steady state (four hours after MCA occlusion).

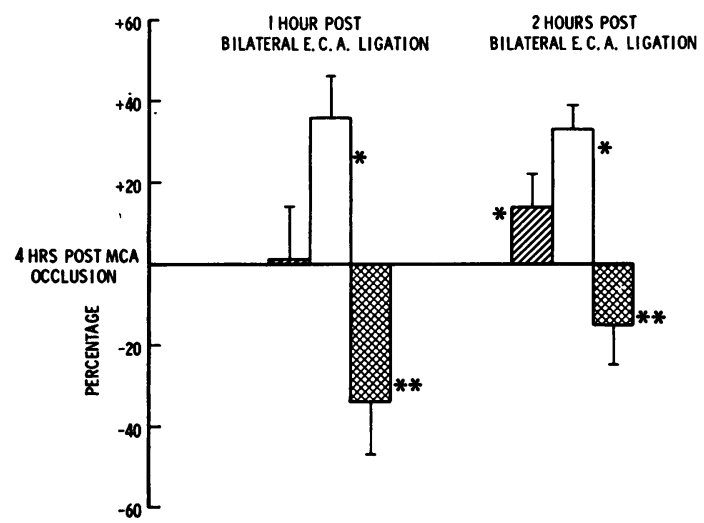

FIG. 5 Percentage change in grey matter flow after middle cerebral artery occlusion followed by bilateral external carotid artery ligation.

* $P<0.05$. ** $P<0.025$. Hatching = non-ischaemic area. White $=$ ischaemic area. Cross-hatching $=$ hyperaemic area. $S S=$ steady state (four hours after MCA occlusion).

Percentage changes in $\mathrm{rCBF}_{10}$ at five and six hours after MCA occlusion in the group without bilateral ECA occlusion are shown in Fig. 2 and the mean blood flow values in Tables 3,5 , and 7 . The gradual but progressive decrease of flow may be noted to occur primarily in areas con- sidered 'non-ischaemic' or 'hyperaemic' in the $z$ steady state. The effect of bilateral external carotid artery ligation on $\mathrm{rCBF}_{10}$ of the hemi- $\infty$ sphere rendered ischaemic by MCA occlusion is displayed in Fig. 3. The procedure produced 0 significant changes in 'ischaemic' and 'hyperaemic' areas with no significant change in nonischaemic zones (compare Figs 2 and 3 ).

Since $\mathrm{rCBF}$ values obtained by stochastic analysis represent an average estimation of $\stackrel{5}{+}$ haemodynamic change in both grey and white $\frac{}{\bar{C}}$

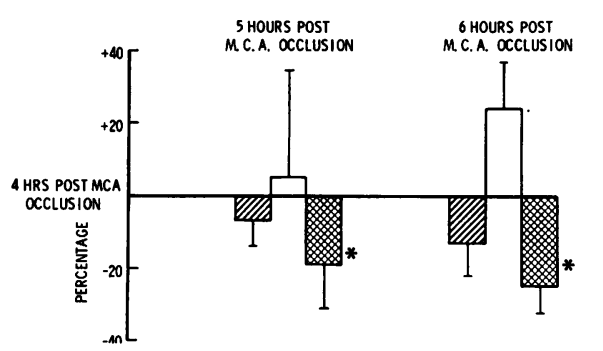

FIG. 6 Percentage change in white matter flow aftier음 middle cerebral artery occlusion.

$* P<0.05$. Hatching = non-ischaemic area. White ischaemic area. Cross-hatching=hyperaemic areg. $S S=$ steady state (four hours after MCA occlusio

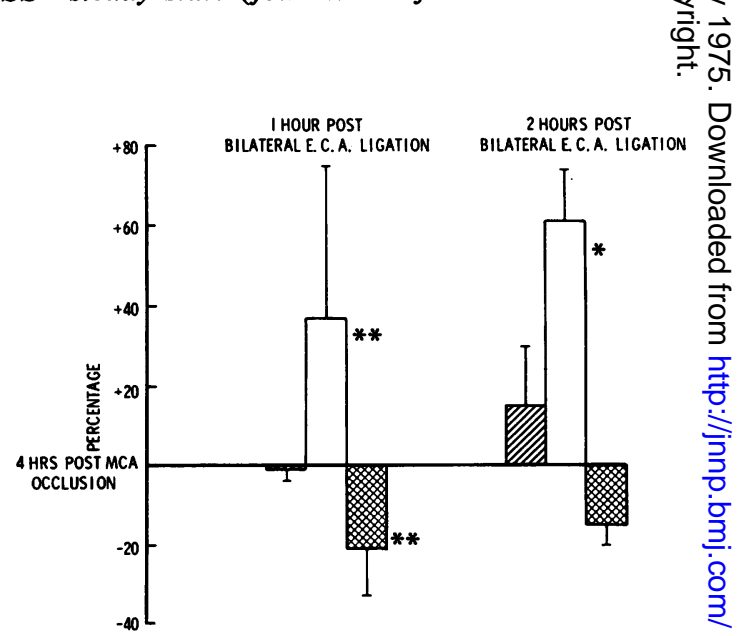

FIG. 7 Percentage change in white matter flow after 5 middle cerebral artery occlusion followed by bilatera 5 external carotid artery ligation.

${ }^{*} P<0.05 .{ }^{* *} P<0.025$. Hatching = non-ischaemic area. White $=$ ischaemic area. Cross-hatching $=$ hyper aemic area. $S S=$ steady state (four hours after MCAN occlusion). 
TABLE 6

MEAN REGIONAL FLOW VALUES IN HYPERAEMIC AREA AFTER MIDDLE CEREBRAL ARTERY OCCLUSION FOLLOWED BY EXTERNAL CAROTID ARTERY LIGATION

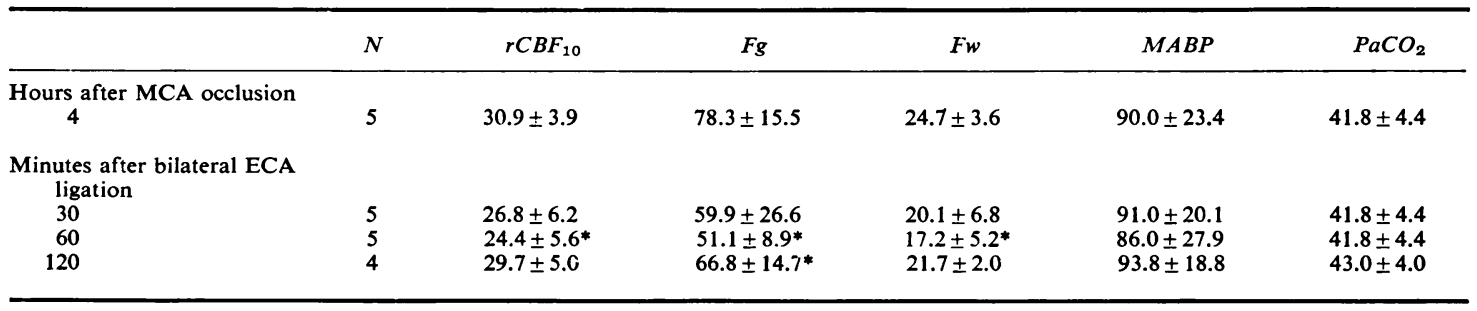

$N=$ Number of cases. Units as in Table 1 .

* Statistically significant compared with four hours after MCA occlusion $(P<0.025)$.

TABLE 7

MEAN REGIONAL FLOW VALUES IN NON-ISCHAEMIC AREA AFTER MIDDLE CEREBRAL ARTERY OCCLUSION

\begin{tabular}{llllll}
\hline & $N$ & $r C B F_{10}$ & $F g$ & $F w$ & $M A B P$ \\
\hline Hours after MCA occlusion & & & & & \\
4 & 4 & $30.2 \pm 1.3$ & $58.0 \pm 6.8$ & $19.8 \pm 3.5$ & $96.3 \pm 14.9$ \\
5 & 4 & $27.1 \pm 2.3$ & $50.4 \pm 2.4$ & $18.3 \pm 2.5$ & $98.8 \pm 16.5$ \\
6 & 4 & $25.4 \pm 3.2^{*}$ & $51.3 \pm 6.4$ & $17.2 \pm 3.6$ & $98.8 \pm 16.5$ \\
\hline
\end{tabular}

$N=$ Number of cases. Units as in Table 1.

* Statistically significant compared with four hours MCA occlusion $(P<0.05)$.

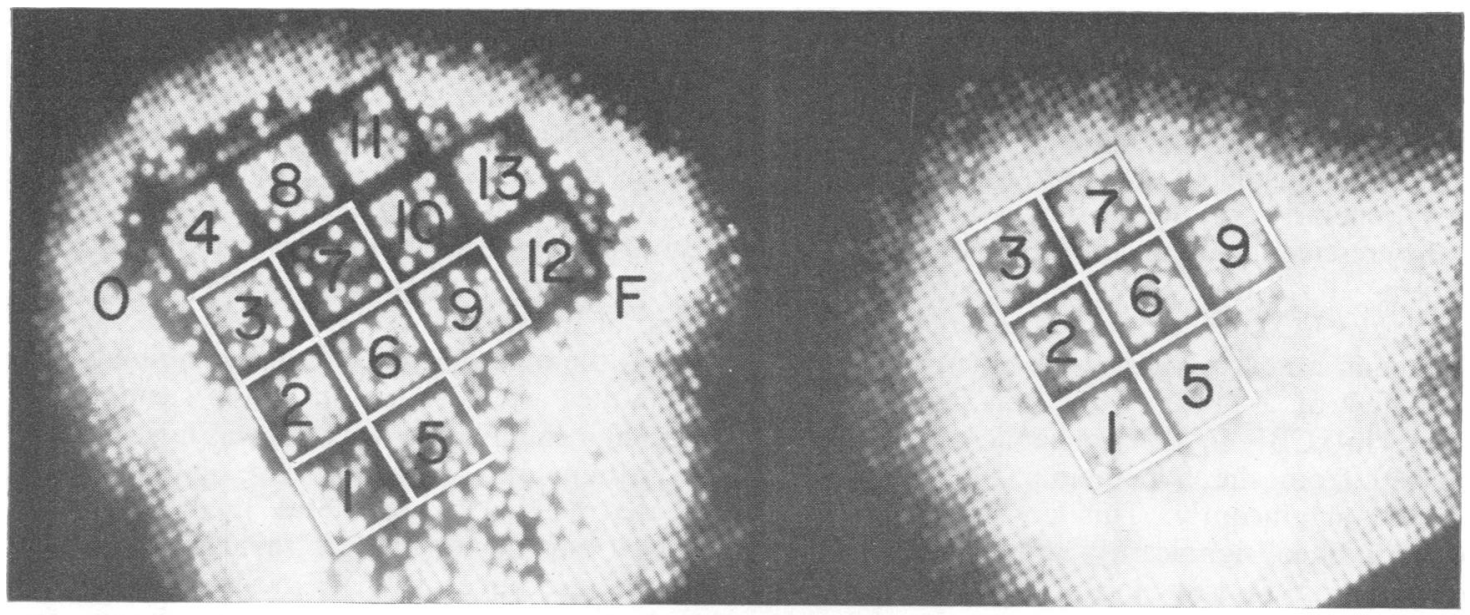

(a)

(b)

FIG. 8 Comparison of ${ }^{133}$ Xe clearance after injection into the ipsilateral ICA (a) and injection into the distal $M C A$ (b) photographed on the grid after MCA occlusion. Regions outlined with white represent the territory visualized by injection of ${ }^{133}$ Xe into the MCA stump (b). 
TABLE 8

MEAN REGIONAL FLOW VALUES IN NON-ISCHAEMIC AREA AFTER MIDDLE CEREBRAL ARTERY OCCLUSION FOLLOWED BY EXTERNAL CAROTID ARTERY LIGATION

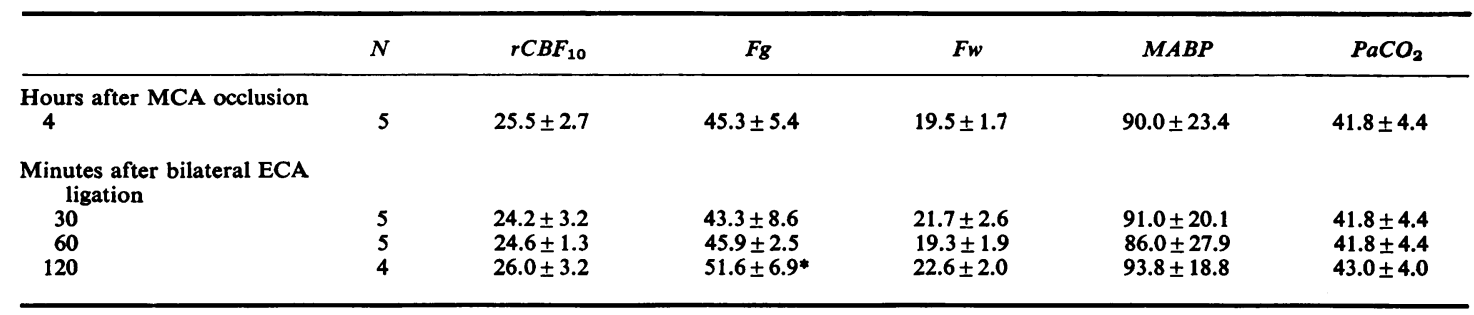

$N=$ Number of cases. Units as in Table 1.

* Statistically significant compared with four hours MCA occlusion $(P<0.025)$.

TABLE 9

GREY MATTER FLOW (ML/100 G/MIN) IN ISCHAEMIC AREA EVALUATED BY INTERNAL CAROTID ARTERY AND MIDDLE CEREBRAL ARTERY INJECTION

\begin{tabular}{|c|c|c|c|c|c|c|c|}
\hline & \multicolumn{7}{|c|}{ Selected region } \\
\hline & 1 & 2 & 3 & 5 & 6 & 7 & 9 \\
\hline \multicolumn{8}{|c|}{ Four hours after MCA occlusion } \\
\hline $\begin{array}{l}\text { ICA injection } \\
\text { MCA injection }\end{array}$ & $\begin{array}{l}4.00 \\
0.11\end{array}$ & $\begin{array}{r}11.20 \\
9.34\end{array}$ & $\begin{array}{r}10.80 \\
9.05\end{array}$ & $\begin{array}{r}82.01 \\
2.66\end{array}$ & $\begin{array}{l}46.33 \\
38.21\end{array}$ & $\begin{array}{l}141.22 \\
132.91\end{array}$ & $\begin{array}{l}43.43 \\
69.34\end{array}$ \\
\hline \multicolumn{8}{|c|}{ Two hours after bilateral ECA ligation } \\
\hline $\begin{array}{l}\text { ICA injection } \\
\text { MCA injection }\end{array}$ & $\begin{array}{r}26.84 \\
7.70\end{array}$ & $\begin{array}{l}23.74 \\
14.40\end{array}$ & $\begin{array}{l}33.98 \\
13.92\end{array}$ & $\begin{array}{r}48.51 \\
0.60\end{array}$ & $\begin{array}{r}37.37 \\
137.63\end{array}$ & $\begin{array}{r}153.31 \\
33.92\end{array}$ & $\begin{array}{l}47.46 \\
91.44\end{array}$ \\
\hline
\end{tabular}

ICA injection $=$ injection of ${ }^{133} \mathrm{Xe}$ into internal carotid artery.

MCA injection = injection of ${ }^{133} \mathrm{Xe}$ into middle cerebral artery stump.

matter, compartmental analysis was performed in order to clarify any specific effects of bilateral external carotid artery ligation on the fast flow, generally considered flow grey $(\mathrm{Fg})$ and slow flow, generally considered flow white $(\mathrm{Fw})$.

Progressive changes in the fast flow component, Fg, after MCA occlusion without bilateral ECA occlusion occurred in the ischaemic and hyperaemic areas (Fig. 4). They consisted of a gradual but non-significant increase in $\mathrm{rCBF}$ in the ischaemic area possibly derived from the hyperaemic zone which decreased significantly. This consistent response was modified significantly after bilateral ECA ligation (Fig. 5). Flow in the ischaemic and nonischaemic areas was greatly enhanced and flow in hyperaemic areas was significantly reduced, presumably since they had provided collateral circulation to the ischaemic zone with a favourable redistribution (compare Tables 3 to 8 ).
The effect of bilateral ECA ligation was not limited to $\mathrm{Fg}$ but also significantly influenced Fw (compare Fig. 6 with Fig. 7). The pattern of changes in $\mathrm{Fw}$ was almost identical with that of Fg. Actual flow values are listed in Tables 3 to 8.

In order to define the zone of rCBF supplied by the MCA in accurate fashion, the distal stump of the middle cerebral artery was cannulated at the time of occlusion in two animals and 30 minutes after evaluation of the steady state (Fig. 8a) a small bolus $(0.25 \mathrm{ml})$ was injected into the stump and the clearance measurement repeated (Fig. 8b). Bilateral ligation of the external carotid artery was then accomplished and the clearance of ${ }^{133} \mathrm{Xe}$ measured from the MCA territory reassessed at two hours for comparison with values obtained by internal carotid injection. The territory supplied by the MCA as defined by direct injection of ${ }^{133} \mathrm{Xe}$ corresponded to the ischaemic zone defined by 
rCBF values after ICA injection. The results of both methods of injection indicated a definite increase in regional flow values in the MCA territory after bilateral ECA ligation (Table 9).

\section{DISCUSSION}

VALIDITY OF EXPERIMENTAL MODEL OF CEREBRAL ISCHAEMIA The technique of transorbital MCA occlusion practised in this laboratory is similar to that described by several authors (Sundt and Waltz, 1966; Hudgins and Garcia, 1970) and is relatively atraumatic compared with other surgical procedures. The general surgical preparation was accomplished with minimal blood loss and shock judging from the blood pressure, haemoglobin, haematocrit, and $\mathrm{PaCO}_{2}$ levels before and after blood flow measurements.

The anatomy of the extracranial and intracranial vessels in the baboon has been studied extensively and the anatomy encountered in the present study was similar to standard descriptions in the literature (Watts, 1934; Campbell and Forster, 1944; Dyrud, 1944; Coceani and Gloor, 1966).

It is believed that a small bolus of ${ }^{133} \mathrm{Xe}$ injected into the distal stump of the MCA provided accurate assessment of its territory of supply. As judged by this method of approach, the size of the territory perfused by the MCA was approximately $80 \%$ of the hemisphere, although the collateral vessels were undoubtedly dilated and ${ }^{133} \mathrm{Xe}$ is highly diffusible so that this is unquestionably an overestimation. The technique of regional injection established the validity of the lower $\mathrm{rCBF}$ values obtained which were often as low as $0.5-2 \mathrm{ml} / 100 \mathrm{~g}$ brain/min (Table 9). Excision of the skin and temporalis muscle was considered essential to avoid extracranial contamination and to obtain such low values (James et al., 1969).

VALIDITY OF REGIONAL BLOOD FLOW MEASUREMENTS USING GAMMA CAMERA Advantages and limitations of the gamma camera for measurement of rCBF have been discussed in detail elsewhere (Heiss et al., 1972; Mathew et al., 1972). Blood-brain partition coefficients were calculated according to the animals' actual haemoglobin and haematocrit values, but these did not alter significantly throughout the study. However, present lack of knowledge of precise partition coefficients for infarcted brain tissue necessitates certain assumptions concerning their selection (Veall and Mallett, 1965; Wilkinson et al., 1969; Olesen et al., 1971; Rees et al., 1971; Rees et al., 1971-72).

The coexistence of ischaemic and hyperaemic areas is based on generally accepted modes of calculation. Despite reproducibility of the technique $(5.2 \pm 1.2 \%)$, interregional variation in non-infarcted baboon brains did not exceed $10 \%$; the assumption of a $20 \%$ interregional variation coefficient in infarcted animals was used since after MCA occlusion the interregional variation rose to $16.7 \pm 3.3 \%$ by actual calculation as might be expected.

Pathological changes demonstrated by electron microscopy four hours after the onset of ischaemia have been reported from this laboratory in similar experimental models of ischaemia (Dodson et al., 1973) and are characterized in four hours by perivascular swelling of the astrocytic end feet and in six hours by loss of cytoplasmic background density due to oedema and structural changes of organelles. The astrocytic nucleus appears intact. Oedema of the white matter with softening is evident grossly at this time. The blood-brain barrier is functionally disrupted, and extravasation of proteins may occur (Olsson et al., 1971) despite apparent structural integrity (Garcia et al., 1971). The structural integrity of the small cerebral vessels at this stage is pertinent to the present study since there is the possibility of increase in collateral blood flow to the ischaemic area that may be favourably influenced by manoeuvres such as ECA ligation.

HAEMODYNAMICS OF ISCHAEMIC AREA An ischaemic area of the brain may be defined in terms of rCBF measurements as those regions supplied by an occluded artery such as the MCA in which rCBF values are reduced $15-20 \%$ below mean hemispheric flow values (Fieschi et al., 1968; Prosenz et al., 1974). The sequence of haemodynamic events that occur in ischaemic regions four, five, and six hours after MCA occlusion is most evidently shown by changes in $\mathrm{Fg}$ and $\mathrm{Fw}$ determined by compartmental analysis. There is progressive but not significant diminution in $\mathrm{rCBF}_{10}$ determined by stochastic analysis after MCA occlusion; Fg and Fw show 
a tendency to increase but this was not significant (Table 3). The tendency to increase in Fg and Fw may indicate vasodilatation in the ischaemic zone due to changes in local metabolic activity such as accumulation of acid metabolites (Lassen, 1966; Hфedt-Rasmussen et al., 1967; Waltz and Sundt, 1967; Halsey and Leland, 1970).

After bilateral ECA ligation the increase of flow in the ischaemic area became significant due to a redistribution of blood from the bordering hyperaemic and non-ischaemic zones, perhaps due to an increased perfusion pressure after bilateral ECA occlusion (Table 4). The redistribution of blood flow to an ischaemic area of the brain has been the subject of study by many authors who have shown the importance of arterioarterial anastomosis interregionally and via the leptomeninges (Vander Eecken and Adams, 1953; Mount and Taveras, 1957; Weidner et al., 1965; Yamamoto et al., 1971). When both external carotid arteries are ligated, flow through the internal carotid increases (Abraham et al., 1971) and cerebral perfusion is improved with redistribution to the ischaemic zone.

HAEMODYNAMICS OF HYPERAEMIC AREA The hyperaemic area may be defined as those regions with regional blood flow values $15-20 \%$ above the mean flow. Bordering hyperaemic zones appeared as early as two to three hours after infarction. A gradual decrease in Fw and Fg of the hyperaemic zone was observed over the next two hours, and $\mathrm{rCBF}_{10}$ likewise decreased (Table 5). After bilateral ECA ligation the significant reduction in hemispheric blood flow (mean $\mathrm{rCBF}_{10}$ ) was reversed or minimized. The significant hyperaemia in Fg was reduced two hours after bilateral ECA ligation. The significant decrease in Fw was no longer evident two hours later (Table 6). Hence, bilateral external carotid ligation produced readjustment of $\mathrm{rCBF}$ toward normal.

The phenomenon of increased blood flow in areas neighbouring or within the territory of an ischaemic zone after arterial occlusion has been reported (Meyer et al., 1954; Lassen, 1966; Hodt-Rasmussen et al., 1967; Fieschi et al.,
1968; Sundt et al., 1971). Increased collateral blood flow was considered an important factor but later the term 'luxury perfusion syndrome' was coined to describe many aspects of this phenomenon, since it was considered as the manifestation of vasoparalysis or maximum vasodilatation secondary to increased tissue acidosis combined with increased local perfusion pressure.

HAEMODYNAMICS OF NON-ISCHAEMIC AREA The remaining regions showing essentially normal flow values, arbitrarily termed non-ischaemic areas, revealed a gradual reduction as measured by hemispheric blood flow $\left(\mathrm{rCBF}_{10}\right)$, as well as measured by bicompartmental analysis of the socalled 'grey' and 'white' matter (Table 7). Gradual reduction of blood flow in areas of relatively normal flow neighbouring the infarct may be caused by progressive oedema spreading from the infarcted zone. Decreases in blood flow remote from the area of acute cerebral infarction and affecting the non-infarcted hemisphere have been reported previously (H $\phi$ edt-Rasmussen and Skinhoj, 1964; Skinhoj, 1965; Meyer et al., 1970). After bilateral ECA, a tendency for $\mathrm{rCBF}_{10}$ and $\mathrm{Fw}$ to increase was noted, whereas Fg increased significantly (Table 8).

Augmentation of cerebral blood flow to areas rendered ischaemic by occlusion of cerebral blood vessels has been an elusive goal to attain in experimental models as well as in patients. It has been attempted unsuccessfully by elevation of systemic blood pressure by pharmacological means (Farhat and Schneider, 1967) and experimentally by intermittent occlusion of the descending aorta just below the origin of the brachiocephalic vessels by a balloon passed via the femoral artery. The latter manoeuvre increased pressure and flow in the common carotid artery and induced a $40 \%$ increase of rCBF in the 'normal' brain of the dog as determined by the krypton-85 washout (Simeone et al., 1972).

Bilateral external carotid artery ligation is a relatively simple surgical technique and appears haemodynamically beneficial to recent cerebral infarction due to occlusive disease of intracranial vessels. Obviously it would be contraindicated if occlusive disease were present in the internal carotid and/or vertebral arteries in the neck. 


\section{REFERENCES}

Abraham, J., Shetty, G., and Chandy, J. (1971). Preliminary observation on the hemodynamics of the internal carotid artery following bilateral external carotid ligation in the monkey. Journal of Neurosurgery, 35, 192-196.

Abraham, J., and Daniel, M. V. (eds) (1972). Aspects of Cerebrovascular Disease in India, pp. 99-102. Diocesan Press: Madras.

Brantigan, J. W., Gott, V. L., and Martz, M. N. (1972). A Teflon membrane for measurement of blood and intramyocardial gas tensions by mass spectroscopy. Journal of Applied Physiology, 32, 276-282.

Campbell, J. B., and Forster, F. M. (1944). The anterior cerebral artery in the macaque monkey (Macaca mulatta). Journal of Nervous and Mental Disease, 99, 229-242.

Coceani, F., and Gloor, P. (1966). The distribution of the internal carotid circulation in the brain of the macaque monkey (Macaca mulatta). Journal of Comparative Neurology, 128, 419-430.

Dodson, R. F., Kawamura, Y., Aoyagi, M., Hartmann, A., and Cheung, L. W. (1973). A comparative evaluation of the ultrastructural changes following induced cerebral infarction in the squirrel monkey and baboon. Cytobios, 8, 175182.

Dyrud, J. (1944). The external carotid artery of the rhesus monkey (Macaca mulatta). Anatomical Record, 90, 17-22.

Farhat, S. M., and Schneider, R. C. (1967). Observations on the effect of systemic blood pressure on intracranial circulation in patients with cerebrovascular insufficiency. Journal of Neurosurgery, 27, 441-445.

Fieschi, C., Agnoli, A., Battistini, N., Bozzao, L., and Prencipe, M. (1968). Derangement of regional cerebral blood flow and of its regulatory mechanisms in acute cerebrovascular lesions. Neurology (Minneap.), 18, 11661179.

Garcia, J. H., Cox, J. V., and Hudgins, W. R. (1971). Ultrastructure of the microvasculature in experimental cerebral infarction. Acta Neuropathologica (Berl.), 18, 273-285.

Halsey, J. H., Jr, and Leland, L. C., Jr (1970). Some regional circulatory abnormalities following experimental cerebral infarction. Neurology (Minneap.), 20, 238-246.

Harper, A. M., Deshmukh, V. D., Rowan, J. O., and Jennett, W. B. (1972). The influence of sympathetic nervous activity on cerebral blood flow. Archives of Neurology, 27, 1-6.

Heiss, W.-D., Prosenz, P., and Roszuczky, A. (1972). Technical considerations in the use of a gamma camera 1,600-channel analyzer system for the measurement of regional cerebral blood flow. Journal of Nuclear Medicine, 13, 534-543.

Høedt-Rasmussen, K., and Skinhøj, E. (1964). Transneural depression of the cerebral hemispheric metabolism in man. Acta Neurologica Scandinavica, 40, 41-46.

Høedt-Rasmussen, K., Skinhøj, E., Paulson, O., Ewald, J., Bjerrum, J. K., Fahrenkrug, A., and Lassen, N. A. (1967). Regional cerebral blood flow in acute apoplexy. The 'luxury perfusion syndrome' of brain tissue. Archives of Neurology, 17, 271-281.

Hudgins, W. R., and Garcia, J. H. (1970). Transorbital approach to the middle cerebral artery of the squirrel monkey: a technique for experimental cerebral infarction applicable to ultrastructural studies. Stroke, 1, 107-111.

James, I. M., Millar, R. A., and Purves, M. J. (1969). Observations on the extrinsic neural control of cerebral blood flow in the baboon. Circulation Research, 25, 77-93.

Lassen, N. A. (1966). The luxury-perfusion syndrome and its possible relation to acute metabolic acidosis localised within the brain. Lancet, 2, 1113-1115.
Mathew, N. T., Meyer, J. S., Bell, R. L., Johnson, P. C., and Neblett, C. R. (1972). Regional cerebral blood flow and blood volume measured with the gamma camera. Neuroradiology, 4, 133-140.

Meyer, J. S., Fang, H. C., and Denny-Brown, D. (1954). Polarographic study of cerebral collateral circulation. Archives of Neurology and Psychiatry, 72, 296-312.

Meyer, J. S., Shinohara, Y., Kanda, T., Fukuuchi, Y., Ericsson, A. D., and Kok, N. K. (1970). Diaschisis resulting from acute unilateral cerebral infarction. Archives of Neurology, 23, 241-247.

Meyer, J. S., Yoshida, K., and Sakamoto, K. (1967). Autonomic control of cerebral blood flow measured by electromagnetic flowmeters. Neurology (Minneap.), 17, 638-648.

Mount, L. A., and Taveras, J. M. (1957). Arteriographic demonstration of the collateral circulation of the cerebral hemispheres. Archives of Neurology and Psychiatry (Chic.), 78, 235-253.

Olesen, J., Paulson, O. B., and Lassen, N. A. (1971). Regional cerebral blood flow in man determined by the initial slope of the clearance of intra-arterially injected ${ }^{133} \mathrm{Xe}$. Stroke, 2, 519-540.

Olsson, Y., Crowell, R. M., and Klatzo, I. (1971). The bloodbrain barrier to protein tracers in focal cerebral ischemia and infarction caused by occlusion of the middle cerebral artery. Acta Neuropathologica (Berl.), 18, 89-102.

Prosenz, P., Heiss, W.-D., Tschabitscher, H., and Ehrmann, L. (1974). The value of regional cerebral blood flow measurements compared to angiography in the assessment of obstructive neck vessel disease. Stroke, 5, 19-31.

Rees, J. E., Bull, J. W. D., Du Boulay, G. H., Marshall, J., Russell, R. W. R., and Symon, L. (1971). The comparative analysis of isotope clearance curves in normal and ischemic brain. Stroke, 2, 444-451.

Rees, J. E., Bull, J. W. D., Du Boulay, G. H., Marshall, J., Russell, R. W. R., and Symon, L. (1971/72). A comparison of stochastic, compartmental and flow initial analysis of rCBF data in a group of normal and ischaemic patients. European Neurology, 6, 213-217.

Simeone, F. A., Laurent, J. P., Trepper, P. J., Brown, D. J., and Cotter, J. (1972). Experimental augmentation of cerebral blood flow by intermittent aortic occlusion. Journal of Neurosurgery, 36, 700-713.

Skinhøj, E. (1965). Bilateral depression of CBF in unilateral cerebral diseases. Acta Neurologica Scandinavica, 41, Suppl. $14,161-163$.

Sundt, T. M., Jr, and Waltz, A. G. (1966). Experimental cerebral infarction: retro-orbital, extradural approach for occluding the middle cerebral artery. Mayo Clinic Proceedings, 41, 159-168.

Sundt, T. M., Jr, and Waltz, A. G. (1971). Cerebral ischemia and reactive hyperemia. Studies of cortical blood flow and microcirculation before, during, and after temporary occlusion of middle cerebral artery of squirrel monkeys. Circulation Research, 28, 426-433.

Vander Eecken, H. M., and Adams, R. D. (1953). The anatomy and functional significance of the meningeal arterial anastomosis of the human brain, Journal of Neuropathology and Experimental Neurology, 12, 132-157.

Veall, N., and Mallett, B. L. (1965). The partition of trace amounts of xenon between human blood and brain tissues at $37^{\circ} \mathrm{C}$. Physics in Medicine and Biology, 10, 375-380.

Waltz, A. G., and Sundt, T. M., Jr (1967). The microvasculature and microcirculation of the cerebral cortex after arterial occlusion. Brain, 90, 681-696.

Watts, J. W. (1934). A comparative study of the anterior cerebral artery and the circle of Willis in primates. Journal of Anatomy, 68, 534-550. 
Weidner, W., Hanafee, W., and Markham, C. H. (1965). Intracranial collateral circulation via leptomeningeal and rete mirabile anastomoses. Neurology (Minneap.), 15, 3948.

Wilkinson, I. M. S., Bull, J. W. D., Du Boulay, G. H., Marshall, J., Russell, R. W. R., and Symon, L. (1969). Regional blood flow in the normal cerebral hemisphere.
Journal of Neurology, Neurosurgery, and Psychiatry, 32, 367-378.

Yamamoto, Y. L., Phillips, K. M., Hodge, C. P., and Feindel, W. (1971). Microregional blood flow changes in experimental cerebral ischemia. Effects of arterial carbon dioxide studied by fluorescein angiography and xenon ${ }^{133}$ clearance. Journal of Neurosurgery, 35, 155-166.

$\stackrel{c}{\mathbb{D}}$ 